\title{
Effects of Aminoquinolines in COVID-19 Treatment: Hydroxychloroquine and Chloroquine
}

\author{
Abdullahi Ishaq ${ }^{1,2,{ }^{*}, \text { Uwais Aminu }}{ }^{1,2}$ and Faisal Muhammad (DD ${ }^{1}$ \\ ${ }^{1}$ Department of Public Health, Faculty of Allied Health Sciences, Daffodil International University, Dhaka, Bangladesh \\ ${ }^{2}$ Health Med Science Research Limited, Dhaka, Bangladesh \\ "Corresponding author: Department of Public Health, Daffodil International University (DIU), 102 and 102/1 Shukrabad, Mirpur Road Dhanmondi, Dhaka, Bangladesh. Email: \\ abdullahiishaq60@gmail.com \\ Received 2020 July 16; Accepted 2020 July 29.
}

Keywords: Hydroxychloroquine, Chloroquine, COVID-19, Public Health

\section{Dear Editor,}

The novel coronavirus disease 2019 (COVID-19) continues to spread quickly across the globe. The COVID-19 infected people were reported from 216 countries across the world by June 11, 2020. To date, 7,145,385 people have been confirmed positive with COVID-19, leading to 408,025 deaths (1). Up to date, many clinical trials have been conducted to investigate an effective and sound therapeutic regimen for COVID-19. Chloroquine (CQ) therapy is among the accepted regimens (2). The aminoquinoline groups have been used for malaria treatment, and they showed to be effective against the COVID-19 virus in many trials (3). A significant role was observed for chloroquine phosphate in the management of SARS-CoV epidemics and the Zika virus. Chloroquine acts by playing a significant role in elevating the $\mathrm{pH}$ of intracellular vacuoles and adjusting the protein degradation pathways, which goes though the acidic hydrolases in the macromolecule and synthesis of lysosomes in the endosomes and post-translational protein modification in the Golgi apparatus. In some antigenpresenting cells and macrophages, CQ normally interferes with antigen processing, hence showing an antirheumatic action (4). Several studies have reported the efficacy of CQ in COVID-19 patients at different stages of severity $(3,5)$. In an in vitro study conducted in China among the results that were earlier obtained, more than 100 patients showed a high level of CQ efficacy and a great improvement compared to a control group based on the reduction of exacerbations of pneumonia, as well as the duration of symptoms and the delay of viral clearance $(3,5)$. Chloroquine phosphate demonstrated a marked efficacy and acceptable safety in treating COVID-19 in a clinical trial conducted in China (3).
Before the 2019 SARS-CoV-2 pandemic, several in vitro studies evaluated the effects of CQ on inhibiting the replication of SARS-CoV (6). According to some studies performed on SARS-CoV, it was also agreed that COVID-19 goes through cells by attaching and sticking to the angiotensinconverting enzyme 2 (ACE-2) receptor, and the CQ may prevent the virus from binding to the ACE-2 receptor by inhibiting terminal glycosylation (6). A recent review on the efficacy and safety of CQ for COVID-19 concluded that while there are sufficient safety data from the long-term use of chloroquine and its derivatives for a variety of indications, there is an ongoing need for further data on the use of chloroquine in COVID-19 (7). In the liver, both CQ and HCQ are metabolized with renal excretion of some metabolites; hence, renal and liver function must be taken into account when using these medications $(8,9)$. However, using aminoquinolines, chloroquine, and hydroxychloroquine, has shown greater activity to stop up viral entry into cells by inhibiting the proteolytic processing, glycosylation of host receptors, and endosomal acidification. To determine whether chloroquine and hydroxychloroquine are therapeutically safe and effective for the treatment of COVID-19, further research might be needed for both primary and secondary care.

\section{Footnotes}

Authors' Contribution: Manuscript drafting: Abdullahi Ishaq and Uwais Aminu. Manuscript editing: Faisal Muhammad.

Conflict of Interests: None.

Funding/Support: None. 


\section{References}

1. Xu B, Kraemer MUG; Open Covid-Data Curation Group. Open access epidemiological data from the COVID-19 outbreak. Lancet Infect Dis. 2020;20(5):534. doi: 10.1016/S1473-3099(20)30119-5. [PubMed: 32087115]. [PubMed Central: PMC7158984].

2. Colson P, Rolain JM, Raoult D. Chloroquine for the 2019 novel coronavirus SARS-CoV-2. Int J Antimicrob Agents. 2020;55(3):105923. doi: 10.1016/j.ijantimicag.2020.105923. [PubMed:32070753]. [PubMed Central: PMC7134866].

3. Gao J, Tian Z, Yang X. Breakthrough: Chloroquine phosphate has shown apparent efficacy in treatment of COVID-19 associated pneumonia in clinical studies. Biosci Trends. 2020;14(1):72-3. doi: 10.5582/bst.2020.01047. [PubMed: 32074550].

4. Rainsford KD, Parke AL, Clifford-Rashotte M, Kean WF. Therapy and pharmacological properties of hydroxychloroquine and chloroquine in treatment of systemic lupus erythematosus, rheumatoid arthritis and related diseases. Inflammopharmacology. 2015;23(5):23169. doi: 10.1007/s10787-015-0239-y. [PubMed: 26246395].
5. Colson P, Rolain JM, Lagier JC, Brouqui P, Raoult D. Chloroquine and hydroxychloroquine as available weapons to fight COVID-19. Int J Antimicrob Agents. 2020;55(4):105932. doi: 10.1016/j.ijantimicag.2020.105932. [PubMed: 32145363]. [PubMed Central: PMC7135139].

6. Vincent MJ, Bergeron E, Benjannet S, Erickson BR, Rollin PE, Ksiazek TG, et al. Chloroquine is a potent inhibitor of SARS coronavirus infection and spread. Virol J. 2005;2:69. doi: 10.1186/1743-422X-2-69. [PubMed: 16115318]. [PubMed Central: PMC1232869].

7. Cortegiani A, Ingoglia G, Ippolito M, Giarratano A, Einav S. A systematic review on the efficacy and safety of chloroquine for the treatment of COVID-19.J Crit Care. 2020;57:279-83. doi: 10.1016/j.jcrc.2020.03.005. [PubMed: 32173110]. [PubMed Central: PMC7270792].

8. Rismanbaf A, Zarei S. Liver and kidney injuries in COVID-19 and their effects on drug therapy; a letter to editor. Arch Acad Emerg Med. 2020;8(1). e17. [PubMed: 32185369]. [PubMed Central: PMC7075271].

9. Wang Y, Zhu LQ. Pharmaceutical care recommendations for antiviral treatments in children with coronavirus disease 2019. World J Pediatr. 2020;16(3):271-4. doi: 10.1007/s12519-020-00353-5. [PubMed: 32166483]. [PubMed Central: PMC7090514]. 